\section{A.R. Mackintosh}

1936-1995

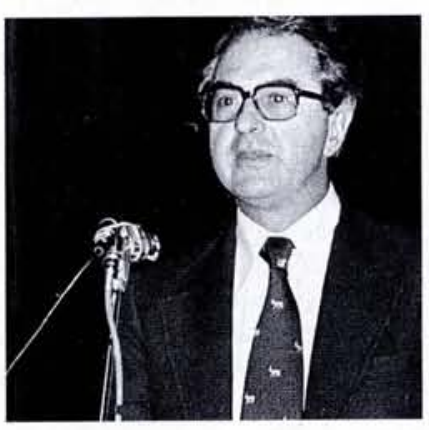

Allan Mackintosh, a former EPS President, was killed in an motor-car accident on 20 December 1995, a month before his 60 th birthday. Allan devoted much of his professional life to studying the behaviour of electrons in solids, notably ferromagnetic metals, and he made decisive contributions to our understanding of the electrical and magnetic properties of the rare-earth metals. His influence was both broad and deep, and many of his former research students now occupy leading academic and industrial positions in several countries. In Denmark, where splendid traditions had been established in astronomy, atomic, nuclear, and particle physics half a century earlier, Allan Mackintosh will be remembered for his successful efforts to establish modern condensed-matter physics. Similarly, through EPS and, more recently, within the context of the European Union, he strove to improve the quality and efficiency of physics research through the internationalization of research.

Allan Roy Mackintosh was born in 1936 in Nottingham. He was educated at Nottingham High School and Peterhouse, Cambridge, where he took his $\mathrm{BA}$ and $\mathrm{PhD}$ degrees. In Cambridge, he also met Jette, his future wife who is Danish. His doctoral research, carried out in the Cavendish Laboratory under the supervision of Professor Sir Brian Pippard, dealt with a study of Fermi surfaces using ultrasonic attenuation in solids.

On leaving Cambridge in 1960 , he took the established route to the USA and became an Associate Professor of Physics at Iowa State University. This appointment was to shape the direction of his scientific career. The University's Ames Laboratory had begun to make crystals of the rare-earth metals. The chemical properties of this group of elements are very similar, so they had only recently been separated into pure forms. However, their physical properties, particularly magnetic properties, are very diverse and were, at the time, unexplored territory for an inquisitive physicist. Allan took up the challenge and soon established himself as a leading expert in this new field.

In 1963 , he spent a sabbatical at the Risø National Laboratory, in Denmark, where a new research reactor had just become operational. Danish physicists were constructing a novel type of neutron spectrometer to measure phonon dispersion in solids. Allan Mackintosh quickly realized the scientific potential of applying the technique to measure spin waves in the rare-earth metals. This was the beginning of a most fruitful collaboration that was to contribute substantially to our understanding of rare-earth magnetism, and which lasted until the last hours of Allan's life.

In 1966, Allan Mackintosh moved permanently to

Denmark and became research professor at the Technical University, Lyngby, where he remained until 1970 . He brought with him from Ames not only precious rare-earth crystals but also computer programs for performing electronic-structure calculations. Allan used them to demonstrate the relevance of computing Fermi surfaces to describe magnetic ordering. He soon taught Danish students how to perform such calculations and asked them to compute the Fermi surfaces of the transition metals, whose complicated d-band sheets were currently being mapped out by the dHvA technique in USA. Only since 1964 had it been known that, unlike the localized 4 f-electrons in the rare-earth metals, the magnetic electrons in the 3d-transition metals contribute to the Fermi surface; the role of the Coulomb correlations between them was a much-discussed topic. Allan had a deep understanding of the behaviour of electrons in metals, and a profound scepticism towards oversimplified theory. His work not only helped to establish the boundaries of the usefulness of destiny-functional calculations for d-and f-band systems but also inspired his students to develop new computational schemes.

Allan became Professor of Experimental Solid-State Physics at the University of Copenhagen in 1970. With his students, his colleagues at Risø, and a number of gifted English postdocs, he continued to improve our understanding of magnetism in the rareearths. He inspired and motivated collaborators, and his research papers, with their carefully constructed prose, are a pleasure to read. The rareearth work was honoured bin 1968 by the award of the prestigious Spedding Prize to Allan Mackintosh and a close colleague from Risø. The culmination of his research was the publication with his former student Jens Jensen of RareEarth Magnetism, a superbly written exposition of the subject. Allan's achievements were recognized by his election as a Fellow of the Royal Danish Academy of Sciences and Letters, the Danish Academy of Technical Sciences, the Royal Norwegian Academy of Sciences, and the Royal Society, London. He was made Knight of the Danebrog order and Uppsala University awarded him an honourary doctorate.

Allan Mackintosh was recognized not only for his superb scientific qualifications and for creating contacts with the best physicists in the world, but also for his fine personality. He never let a colleague or friend drift out of sight and he constantly tried to offer help and support, both professionally and personally. A characteristic of Allan was that he was aware of the importance of the contributions of all his collaborators, and he saw to it that each received full recognition.

Although research was always his main priority, Allan Mackintosh's leadership skills were much in demand. In 1971, when he was just 35 , he became Director of the Risø National Laboratory. Prompted by the oil crisis, Denmark had embarked on a national debate about the development of nuclear power for electricity generation. In the frequently heated atmosphere, Allan needed all his diplomatic skills to steer the discussion with factual rather than emotional arguments. After resuming his university chair in 1976, he belonged to the Board of Governors of Risø from 1978 to 1985 and to the Board of Governors of NORDITA, the Nordic Institute for Theoretical Physics, from 1978 to 1984 . He also served as NORDITA's Director from 1986 to 1989.

As a strong believer in the need for international collaboration, Allan Mackintosh came to play an increasingly important role in physics at the European level. He was President of the Danish Physical Society in 1976-78 and a delegate to the EPS Council, having chaired the EPS Condensed Matter Division's Metal Section in 1970-73. He was elected to the EPS Executive Committee in 1977 , and was the Vice-Treasurer for two years and the Treasurer for one year before serving as the EPS President in 1980-82. His presidency was marked by 
serious questions of scientific freedom that revolved around the Sakharov question, attempts to have the 1981 EPS General Conference moved from Istanbul and restrictions on participation at the 1984 General Conference in Prague, all of which he discussed in some detail in an article in the 25th EPS Anniversary issue of Europhysics News [EN 24 (1993) 118]. He later became a member of the Hewlett-Packard Europhysics Prize Selection Committee, and the committee's chairman from 1986 to 1990. Allan organized the second EPS Large Facilities Conference under the title Symposium on International Facilities for Physics Research (March 1993; Copenhagen and Risø) and was largely responsible for arranging a substantial donation that represented the capital needed to establish the European Journal of Physics.

In the 1990's, Allan's extensive international contacts, his flair for international collaboration and a strong emphasis on quality made him a valued consultant to the European Commission and he chaired the Large-Scale Facilities Panel of the European Union's Framework programme for science. He also remained a knowledgeable commentator on Nordic physics, one of his last contributions being in Europhysics News one year ago. Allan took great pleasure in music, squash, travelling, and a comprehensive collection of malt whisky. He disguised his enjoyment of sport and physical activity behind a facade of feigned mediocrity. On hill-walking holidays he divided his energies between humourous discourses as to the pointlessness of climbing the following hill, and making certain that he was the first at the top. For his ironic sense of humour definitely had a special flavour.

Besides his interest in, and contributions to, modern physics, Allan worked on the history of physics. Here again he was fighting for quality and fairness by pointing out and proving decisive contributions made by little-known scientists to major inventions or discoveries of our century, such as the computer by J.V. Atanasoff and the neutrino by C.D. Ellis.

It is symbolic of his interest in the past as well as the future of physics, that he spent the last day of his life selecting the next experiments to be carried out in 1996 at Risø under the European Union's Framework programme, and then gave an eloquent seminar on the discovery of neutrino. The tragic nature of his sudden death makes the loss all the more acute amongst his worldwide circle of friends and colleagues.

O.K. Andersen (Stuttgart)
K. McEwen (London)
H.B. Møller (Risø)
G. Thomas (Geneva)

Optics, Garching, has accepted an invitation to Chair the Topical Conference Steering Committee made up of QEOD and EUROPTO delegates, and Marcel Ducloy, the QEOD chair, will chair the EPS Topical Conference on Solid-State Lasers at Laser ' 97 (16-20 June 1996). Also decided upon so far is the EUROPTO Topical Conference on Lasers and Environmental Studies. The QEOD is involved in oganizing the European Quantum Electronics Conference part of the biannual EQEC/CLEO conference and exhibition series that was launched in 1994 as aback-to-back event to mirror the North Ameri-

\section{Letters to the Editor}

\section{Rejection Possible}

I read with interest Europhysics News, which is published entirely in English. The use of English implies a cultural impoverishment with regard to the languages of countries whose societies belong to EPS. But publishing editions in all these languages would be too complicated and very expensive, and since Europhysics News essentially contains technical information, the use of English is acceptable. However, I am shocked that by being translated into English, the names of member societies are not respected. It is as if peoples names are translated. It is certainly true that for presentation in alphabetic order it is practical to use the English name, but the society's name in its country should also be preserved (for example: France: Societé Française de Physique). It is also more respectful of cultural and linguistic traditions to write, wherever possible, addresses in a country's language. These addresses are generally entered in a computer file and effort need only be made once to enter a record. Certain addresses are already given in a country's language[see EN 26 (1995) 84-87]; it is that much more disagreeable when this is not the case.

The countries concerned are for the most part relatively poor and weak. Europe's diverse languages and cultures are a source of complication, maybe even misunderstanding, but they represent nonetheless a richness that one must not neglect. If European organizations forget this, a rejection of European cooperation could result.

Jean Peter, LPC/ISMRA, Paris

canI (international)QEC/ CLEO event. EQEC/CLEO aims not to be held in the same year as Laser (the next EQEC/CLEO is in Hamburg on 9-13 September 1996).

Gerard t'Hooft, professor of theoretical physics at Utrecht University, has been awarded one of the new Spinoza awards by the Dutch funding agency NWO. With a total of 12 million HFL shared among four scientists, the awards represent Holland's most valuable scientific prize. His achievements, notably the demonstration of quantum effects in instantons, and efforts to popularise particle physics have also lead to the award of
Ed.: Faced with over many national languages, the Society usually publishes entirely in English. Europhysics News, mindful of the issues raised by the correspondent, sometimes makes the important gesture of adding national society names in their own language if the language is a major one (a practice adopted by many scientific publications for abstracts). Concerning address, international conventions require that national post offices accept letters addressed in English, but in view of the need for reliable addresses, EN publishes, whenever appropriate, society addresses in the major European languages.

\section{Meetings Addresses}

On Page 136 of the Meetings Issue of Europhysics News you have a listing for the American Institute of Physics (AIP) but none for the American Physical Society (APS) and other US-based physics organizations. The matter is further confused since you have separate entries for societies such as the American Geophysical Union. You are perhaps unaware that the AIP, APS, etc. share the same building. By listing meetings under AIP, anyone seeking to get information would be disappointed as the AIP only has a peripheral role.

Irving Lerch, APS, College Park Ed.: Although aware that several organizations share the American Center for Physics in College Park, we aimed to present a concise listing of contacts. To avoid confusion, the Europhysics conference listing on the EPS EurophysNet service (http://epswww.epfl.ch/) has been modified to distinguish events organized by AIP, APS, etc.

doctorate honoris causa from the Catholic University of Leuven.

Rudolf Bock, who formerly chaired the EPS Nuclear Physics Division, retired from GSI, Darmstadt, in December, which he helped found and where he served for 20 years as a member of the Directorate. Peter Braun-Munzinger, Professor at the State University of New York, succeeds him as Director of Nuclear Physics I.

Catherine Bréchignac has been appointed as the Scientific Director of the CNRS Physical Sciences and Mathematics Department, replacing Daniel Thoulouse who became a regional delegate.
Walther, the Director of the MaxPlanck Institute for Quantum 